\title{
A InOVAÇ̃̃o SustentáVEL E A \\ DiNAMIZAÇÃO DO SISTEMA LOCAL DO Agronegócio do Caju Cearense
}

Leonel Gois Lima O liveira

MestradoemAdministracãopda

UniveridadeEstadul dbCerá́- UECE

BdsistaCAPES

leandgais@gmiil.cm

Ana Sílvia Rocha Ipiranga

DattradoemPsidoga De Lavoroe

Dell'arganizzazionepdoUnivesità Degji

Studi Di BdognaeProfessoraA Ajunta da

UnivesidadeEstadual dbCeráá-UECE

anasilviaipi@ud.combr

\section{RESUMO}

O agronegócio do caju do Cearánecessita mais inovações.

Nesse contexto, pressupõe-se que a "inovação sustentável" surgiria com base na gestão so cioambiental, dinamizando, em consequência, o sistema local. Com arrimo nessa discussão, a contribuição do artigo está em identificar as possibilidades de inovações com a introdução da abordagem da Produção Mais Limpa, refletindo sobre a dinamização do sistema local do agronegócio do caju cearense. A metodologia de caráter qualitativa baseou-se na compilação documental e em entrevistas/ debates com um painel constituído por especialistas que atuam no setor. Para a análise, foi utilizada a técnica da Análise Temática que se insere no conjunto das técnicas da A nálise de Conteúdo. Verificou-se que a dinamização do sistema local passa pelo adensamento das interações dos agentes participantes, facilitando a disseminação das inovações sustentáveis com o aproveitamento integral do caju, ampliando, em consequência, os espaços econômicos com novas oportunidades de negócios e mercados.

Palavras-chave: Inovação Sustentável. Sistema Local de Inovação. Cadeia Produtiva do Caju. Produção mais Limpa. Agronegócio do Caju.

\section{ABSTRACT}

Cashewagibusinessin Cerá needsmoreinnovations In this context, it isassumed that "sustainableinnovation" would appear fromsoialenironmental managenent, consequently stimilating thelocal system Based on this disaussion, this paper contributes on theidantification of innovation possibilities thrang the introduction of the Cleaner Production approach, relleting on themdilization of cashew agibusiness local systemin Ceará. Thequalitativem thoddogy is based on dbamental compilationandoninterviens/ debateswitha groupconstituted by expets who work in thesetor. Theamalysis was condurted using the Thematic A nalysis teehnique, which bdongs to the Content A nalysis grap of techniques. It was veified that the local systemmbilization indudes theincresing of interations among partiapant agents, failitating the spread of sustainable innovations for thecompleteuse of cashewand therforeenlarging economicspaces with newbusinessandmarke qpportunities

Key words: SustainableInmovation InmovationLoal System CashewProdurtion Chain Clemer Production CashewAgibusiness 


\section{INTRODUÇÃO}

O agronegócio do caju na região Nordeste possui grande importância socioeconômica para o País em função da área explorada, da quantidade de pessoas empregadas e dos produtos destinados à exportação. Os números demonstram que mais de $90 \%$ da produção está concentrada nos Estados do Piauí, Rio G rande do Norte e Ceará(FIGUEIRÊDO JÚNIOR, 2008). 0 estado do Ceará, como maior produtor nacional, vem articulando um conjunto de ações em prol da organização do sistema local, mediante introdução de inovações, visando ao desenvolvimento da cadeia produtiva do agronegócio do caju que alimenta um parqueindustrial constituído pelas tecnologias sociais das minifábricas, quanto por empresas de pequeno, médio e grande porte (LEITE, 1994; FRANÇA đal., 2008).

Apesar do apoio das diversas organizações que compõem o sistema local de inovação, como as universidades, centros e laboratórios de pesquisa e desenvolvimento (P\&D), agências governamentais de fomento, governos, associações empresariais, visando à geração, adaptação e difusão de inovações, para melhoria dos produtos e 0 aprimoramento de processos, a cadeia produtiva do agronegócio do caju carece de inovações (LUNDVALL, 1992; BELL; PAVITT, 1993). A baixa competitividade das empresas é uma ameaça não somente para as próprias empresas, mas também para as cadeias produtivas dependentes de produtos tradicionais. Um desafio, portanto, é aquele de como conseguir que as empresas criem e/ ou utilizem o conhecimento para inovar (FRANÇA Æal., 2008).

Consideram-se ainda as evidências, segundo Oliveira e Ipiranga (2008), que os especialistas do agronegócio do caju no Ceará, que participam do Pacto de Cooperação da Agropecuária Cearense (AGRO PACTO, 2008), pouco abordam as questões referentes à sustentabilidade, sobretudo, com a integração destas às práticas de inovação no âmbito da cadeia produtiva.

Atualmente a preocupação com a sustentabilidade está em posição de destaque na agenda da inovação, na qual o conceito de "destruição criativa" desenvolvido por Schumpeter (1997) ganha nova roupagem quando pensado juntamente com a sustentabilidade. A visão do processo inovador se amplia para se adequar e envolver não somente o desempenho econômico, mas também 0 ambiental e social (TIDD, BESSANT; PAVITT, 2008; ALMEIDA, 2007).

Berkhoute Green (2002) identificam limitações naliteratura sobre inovação, quando o tema é relacionado com a sustentabilidade, e propõem a ideia da "gestão da inovação sustentável", ao ressaltarem que pouco tem sido feito na literatura sobre negócios emeio ambiente, gestão ambiental e políticas do meio ambiente, para explorar sistematicamente os conceitos, teoria e evidências empíricas desenvolvidas nas últimas três décadas de estudo sobre inovação.

A gestão socioambiental, mediante adoção de abordagens e ferramentas como, por exemplo, o da Produção Mais Limpa (PML), atuante preventivamente na eliminação dos desperdícios, da redução e, consequentemente, do reaproveitamento dos resíduos gerados no processo produtivo, pode apresentarse como fonte de inovação para empresas participantes de cadei- as produtivas (LEMOS, 1998; GASI; FERREIRA, 2006; NAS CIMENTO; LEMOS; MELLO, 2008; CHRISTIE eal, 1995).

Neste contexto, pressupõe-se que a "inovação sustentável" , ao conectar as dimensões ambientais com aquelas econômicas e sociais, surgiria a partir da implementação, no âmbito das empresas participantes da cadeia produtiva, de uma abordagem da gestão socioambiental, como a PML, dinamizando, em consequência, o sistema local. Com base nessa discussão e tendo como foco as empresas participantes da cadeia produtiva da cajucultura, o objetivo deste artigo é identificar as possibilidades de geração e difusão de inovações sustentáveis à luz da abordagem da PML, refletindo sobre a dinamização do sistema local do agronegócio do caju cearense.

E ste trabalho é composto por um referencial teórico articulando os temas das cadeias produtivas e dos sistemas locais de inovação; os tipose espaços de inovação e da gestão da inovação sustentável com a introdução da abordagem da PML. Em seguida são apresentados os recursos metodológicos adotados. Posteriormente, encontram-se a análise e a discussão dos resultados. Finalizando, apresentam-se as considerações e as referências.

\section{CADEIAS PRODUTIVASE SISTE MAS L OCAIS DE IN OVAÇÃO}

O conceito de cadeia produtiva parte da premissa de que a produção de bens pode ser representada como um sistema, onde os diversos agentes estão interconectados por fluxos de materiais, de capital e de informação, objetivando suprir um mercado consumidor (CASTRO ; LIMA; CRISTO, 2002).

No decorrer dos anos 1950, o conceito agibusinessfoi desenvolvido, sendo este introduzido no Brasil com a denominação de "complexo agroindustrial, negócio agrícola e agronegócio", definido não apenas em relação ao que ocorre dentro dos limites das propriedades rurais, mas também no que diz respeito a todos os processos interligados que propiciam a oferta dos produtos da agricultura aos seus consumidores (ZY LBE RSZTAJN, 1994; BATALHA, 2008).

O conceito de agronegócio, todavia, é muito amplo e nem sempre adequado à formulação de estratégias setoriais, principalmente quando se trata de promover a gestão tecnológica ou de inovação e desenvolvimento. Por isso, o conceito foi desenvolvido, adicionalmente, para criar modelos de sistemas dedicados à produção, que incorporassem todos os envolvidos no processo produtivo. D este modo, surgiu o conceito de cadeia produtiva, como subsistema (ou sistemas dentro de sistemas) do agronegócio (CASTRO \&al., 1996).

O s primeiros trabalhos aplicando o enfoque das cadeias produtivas surgiram na década de 1980, tendo sido amplamente expandidos na década de 1990. Contribuiu também para esta expansão o desenvolvimento de ferramentas analíticas consistentes, fundamentando o enfoque sistêmico das cadeias produtivas em estudos e projetos de desenvolvimento, ampliando a compreensão, a intervenção e a gestão no desempenho do agronegócio (CAST RO \&al., 1995, 1998; ZY LBERSZTAJN, 1994; BATALHA, 1995).

Entre estas contribuições, evidencia-se a de Lambert, Cooper e Pagh (1998), que propõem o conceito de SupdyChain 
Management(SCM) como sendo a integração dos processos de uma cadeia produtiva, do ponto de origem até o consumo, com o objetivo de fornecer produtos, serviços e informações com valor agregado aos clientes e outras partes interessadas (stakdhddas) envolvidas ao longo da cadeia.

A análise das cadeias produtivas pode ser baseada em três fatores diferentes - a tecnologia, os mercados e os produtos. A visão estática de uma cadeia produtiva é definida pela superposição desses três fatores. Já a visão dinâmica é obtida pela consideração simultânea desses três elementos ao longo do tempo. Qualquer modificação em um deles pode afetar diretamente os demais. Para facilitar a análise global de uma cadeia, 0 seu escopo deve estar dividido em dois níveis, um vinculado ao seu objetivo principal e outro de atividades indiretas e auxiliares. Em última instância, o mercado consumidor final é que determinará as caracteństicas dos produtos a serem oferecidos. Essas preferências afetam os demais componentes da cadeia produtiva, inclusive os sistemas produtivos locais e os correspondentes sistemas naturais (SO UZA; KLIEMANN NETO, 2002).

Adaptando-se um modelo de Comêa eCorrêa (2004), apresenta-se na Figura 1 uma cadeia produtiva genérica. O s principais elos de uma cadeia produtiva são Fornecedor, Fabricante, Distribuidor, Varejista e Mercado. Entre eles, são realizadas trocas de materiais por valores financeiros. Vale ressaltar que o elo identificado como 'políticas públicas' pode atuar em qualquer um dos elos anteriormente citados. Neste caso, verifica-se uma relação de mão dupla, contendo ações e retroalimentações (feedbadks).
Lundvall (2002), ao considerara inovação como produto da interação de um conjunto de agentes distribuídos em diversas instituições e em lugares distintos, enfatiza a necessidade de integrar mais estreitamente esta base de conhecimento, desenvolvido interativamente e compartilhado em redes, com os processos de aprendizagem e inovação. As organizações participantes das redes inovam não só processando informações de "fora para dentro", com o intuito de resolver os problemas e se adaptar ao ambiente em transformação, mas, também, criando conhecimentos e informações de "dentro para fora", a fim de redefinir tanto os problemas quanto as soluções e, nesse processo, recriar seu meio (NO NAKA; TAKEUCHI, 1995).

Nesse contexto, Lundvall (2002) salienta que a aprendizagem é socialmente vinculada e a iniciativa de organizações e instituições são cruciais para o surgimento das interações e do intercâmbio. Aprender e inovar depende de saberes tácitos, localizados e cumulativos, estando as capacidades de inovação e de aprendizagem fortemente enraizadas na estrutura social, institucional e produtiva de cada região ou país, que podem ser encontrados, por exemplo, em aglomerações de pequenas e médias empresas interligadas ao longo de cadeias produtivas (LO IO LA; RIBEIRO, 2004).

Para Lundvall (2001), as políticas públicas têm diferente e importante papel nesse contexto, ao atuar na formação de redes de empresas e de instituições, reunindo as diversas partes em atividades menores de forma cooperativa, para que essas possam iniciar um trabalho de "mútuo apoio" (LUNDVALL, 2001).

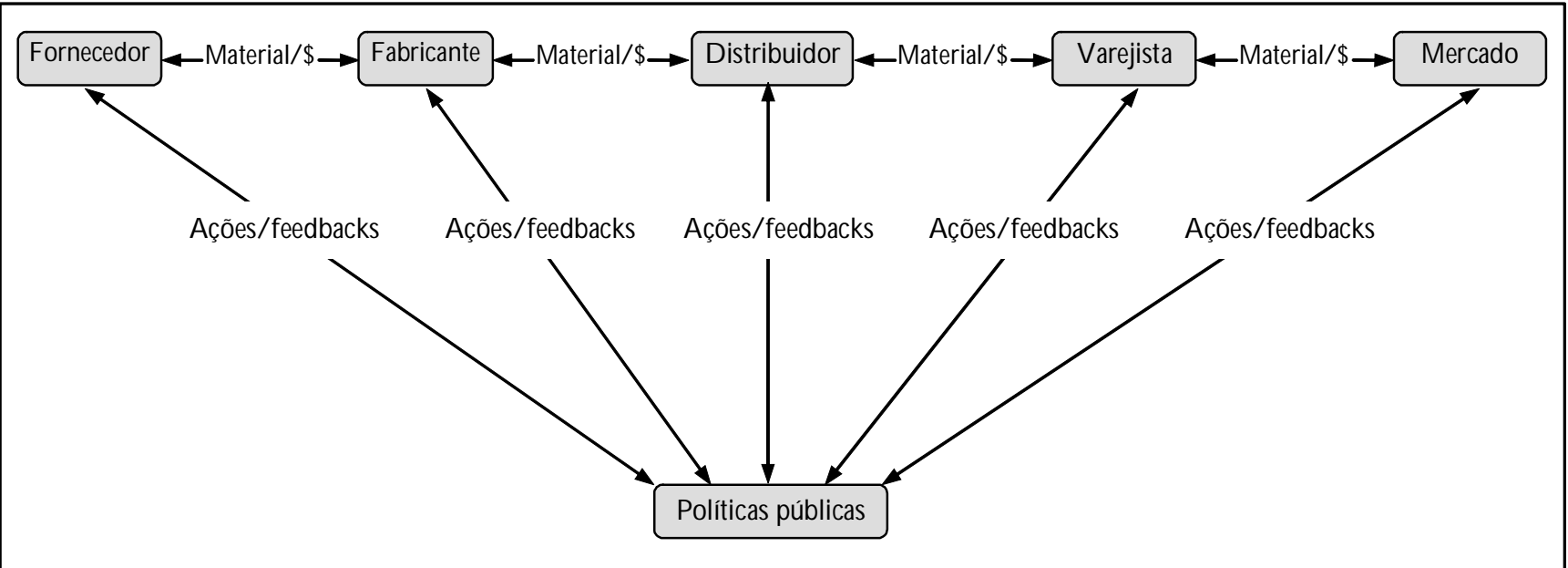

Figura 1: Cadeia produtiva genérica.

Fonte: Adaptado de Corrêa e Corrêa (2004, p. 116).

\section{0s sistemas locais de inovação}

Na assim chamada Economia do Conhecimento, as redes de colaboração constituem espaços mediante os quais ainteração interorganizacional enseja um contexto favorável para a criação, partilha e utilização do conhecimento, envolvendo aspectos como articulação, cooperação, flexibilidade e interdependência das organizações, reforçando a eficácia para que os participantes atinjam um maior nível de competitividade por meio da gestão dos relacionamentos(CASTELLS, 1999; BALE STRIN; VARGAS, 2004).
Esta percepção sobre a natureza sistêmica e complexa da inovação contrapõe-se à noção tradicional característica do chamado "modelo linear", estabelecendo uma sequência bem definida que inicia com as atividades de pesquisa básica e desemboca na adoção de novos produtos e processos nas organizações. Na abordagem sistêmica, ainovação deixa de ser encarada como um fenômeno isolado no tempo e no espaço e passa a ser considerada como o resultado de trajetórias cumulativas efeitas historicamente, de acordo com as especificidades institucionais

CONTEXTUS Revista Contemporânea de Economia e Gestão. Vol.7 - № 1 - jan/ jun/ 2009. (55-68). 
e padrões de especialização econômica inerentes a um determinado contexto espacial ou setorial (VARG AS, 2002).

\section{T ipos e espaços de inovação}

Bell e Pavitt (1993) ensinam que a mudança tecnológica envolve duas principais atividades: a primeira refere-se a geração, desenvolvimento e comercialização de inovações significativas; a segunda baseia-se na aplicação dessas inovações nos processos produtivos e econômicos, sendo esta atividade conhecida como difusão de inovações.

Para Vasconcelos (2001), as "inovações" - como transformações de uma descoberta em uma nova prática - podem ser vistas como reconfigurações de sistemas de atividade econômica, como mudanças de papéis que os agentes econômicos desempenham ao interagir em sistemas de criação de valor. 0 autor diferencia as "microinovações" das "macroinovações". As primeiras são "inovações incrementais" e se relacionam à eficiência das operações atuais, sendo importantes para atingir ganhos operacionais e prover melhorias contínuas nos sistemas de produção. As "macro-inovações" buscam opções para o futuro, sendo fundamentais, pois permitem saltos qualitativos nos sistemas produtivos, nas posições competitivas das empresas e nas configurações da rede de relacionamentos entre os agentes econômicos. Esta última representa "inovações radicais" que criam uma nova configuração de agentes econômicos. Estão ligadas à criação de valores qualitativamente novose implicam a constituição de novas redes de agentes que colaboram para criar constelações de valor.

Esta discussão sobre os diferentes tipos de inovação se articula ao conceito de "espaços econômicos", nos quais aplicações de novasideias e métodos na esfera econômica resultam na dilatação do espaço econômico. Estes são motivados pela percepção de oportunidades de mercado transformadas em ganho pelos agenteseconômicos (BURLAMAQUI; PROENÇA, 2003).

Ressalta-se que os "espaços econômicos" inovadores não se referem apenas ao desenvolvimento científico ou demanda por novas tecnologias, delineando-se também os espaços expressados por Schumpeter (1997) em cinco situações-chave: i) a introdução de um novo bem com o qual os consumidores ainda não estão familiarizados, ou de um novo tipo de bem já existente; ii) introdução de um novo método de produção ainda não testado, não precisando ser baseado em uma descoberta cientificamente nova; iii) a abertura de um mercado, quer esse mercado tenha existido ou não; iv) a conquista de uma nova fonte de suprimento de matérias-primas e demais insumos, independentemente dessa nova fonte existir ou não; e v) estabelecimento de uma nova organização de qualquer indústria.

\section{A gestão da inovação sustentável}

Berkhoute Green (2002) identificam limitações na literatura sobre inovação, quando o tema é relacionado com a sustentabilidade. Encontram-se estudos abordando a utilização de tecnologias ambientais e tecnologias sociais isoladamente, sem uma perspectiva de integração por meio de conceitos como desenvolvimento sustentável ou sustentabilidade. Jabour (2007) aponta, por exemplo, uma diversidade terminológica e conceitual para termos que relacionam aspectos ambientais no desenvolvimento tecnológico.

O conceito "gestão da inovação sustentável" é proposto por Berkhout e Green (2002), ao ressaltarem que pouco tem sido feito na literatura sobre negócios e meio ambiente, gestão ambiental, gestão social e políticas relacionadas a questões sociais e ambientais para explorar sistematicamente os conceitos, teoria e evidências empíricas desenvolvidas nas últimas três décadas de estudo sobre inovação. Merece destaque quanto o trabalhado desenvolvimento por D aroite Nascimento (2004), que apresenta um frameverk ressaltando a integração das dimensões econômica, social e ambiental ao processo de geração de inovações.

O conceito de destruição criativa desenvolvido por Schumpeter (1997) ganha nova roupagem quando pensado juntamente com a sustentabilidade. 0 processo inovador necessita ter uma visão ampliada para se adequar e atingir não somente por meio de seu desempenho econômico, mas também 0 ambiental e social (ALMEIDA, 2007).

Segundo Tidd, Bessant e Pavitt (2008), a preocupação com a sustentabilidade está em posição de destaque na agenda da inovação. Berkhout e Green (2002) sugerem que algumas propostas são apresentadas como forma de associar a pesquisa sobre sustentabilidade à pesquisa sobre política, gestão de negócios e inovação, além de superar as limitações encontradas naliteratura.

D esta forma, a proposta é de que o objeto de análise recaia nos sistemas ou regimes tecnológicos, assim como na sua evolução, no lugar de sua gestão, com base na suposição de que a inovação é consequência da combinação de oportunidade tecnológica com a necessidade do mercado, recomendando-se, ainda, a inclusão de preocupações sociais. Portanto, a sustentabilidade dos negócios está envolvida pelas atitudes sociais que mudam constantemente, ensejando uma oportunidade ao surgimento de uma inovação. Esta poderá simplesmente adequar o negócio aos padrões exigidos pela sociedade ou gerar um novo nível de percepção das atitudes sociais (TIDD; BESSANT; PAVITT, 2008; BERKHOUT; GREEN, 2002).

A sustentabilidade apresenta-se como oportunidade potencial para o surgimento de mercados, além de desafiar os existentes. D esta forma, optou-se por utilizar o conceito, proposto de Berkhout e Green (2002), da "gestão da inovação sustentável", visando a ampliar o entendimento de geração de inovações relacionada não apenas às dimensões ambientais e econômicas, mas incluindo também àquelas sociais.

\section{A GESTÃO SOCIOAMBIENTAL E A ABORDAGEM DA PRO DUÇÃO MAIS LIMPA (PML)}

Entre as diversas abordagens da gestão so cioambiental, destaca-se a da Produção Mais Limpa (PML), desenvolvida no início da década de 1990 pela UnitedNationsIndustrial Dedqumet Organization (Unido) e pela United Nations Environment Programme(UNEP). Apresenta como principal objetivo minimizar ou eliminar os desperdícios comumente encontrados nos processos produtivos: 0 desperdício de matérias-primas e o desperdício de energia.

Em 1994 foram criados centros nacionais ou regionais para a difusão dessa proposta, foram denominados National 
Cleaner ProdurtionCentres (NCPCs). Após dez anos de operação do Programa de Produção Mais Limpa da UNID O-UNEP, verificou-se que este estava operando em 31 países ecom 22 NCPCs, inclusive o Brasil (UNEP, 2006; GASI; FERREIRA, 2006; BARBIERI, 2007; NASCIMENTO; LEMO S; MELLO, 2008).

Conforme a UNEP/ UNID O, a PML consiste numa estratégia ambiental preventiva e integrada, aplicada de maneira continuada, nos processos produtivos, nos produtos e nos serviços, buscando reduzir os riscos relevantes aos homens e ao meio ambiente. As práticas da PML podem ser de pequeno ou grande porte, desde a realização de ajustes até a aquisição de tecnologias complexas, ensejando inovações ao desencadear mudanças nos processos, produtos e formas da gestão das empresas. Estas mudanças propiciam a adoção de abordagens preventivas da poluição, em vez das abordagens "fim-de-tubo" ou "end-ofppipe" (GASI; FERRE IRA, 2006; NASCIMENTO; LEMOS; ME LLO, 2008; CHRISTIE \&al, 1995).

A adoção da PML por uma organização sugere etapas a serem seguidas, visando a melhor compreensão e assimilação dos conceitos e práticas abordados. As fases de implementação da PML no Brasil seguem as orientações do NCPC brasileiro, que busca atuar como um instrumento facilitador para disseminação e implementação da PML em todos os setores e cadeias produtivas (NASCIMENTO; LEMOS; ME LLO, 2008).

O programa desenvolvido no Brasil consiste numa adaptação do programa da UNID O / UNEP e da experiência da Consultoria Stenum, da cidade de Graz, na Áustria, que desenvolveu o Edogical Projet for IntegratedEniramental Techndojes ou mais conhecido como ECO PROFIT. Este apresenta como principal meta o fortalecimento econômico da empresa por meio da prevenção da poluição (LEMO S, 1998; NASCIME NTO; LEMO S; MELLO, 2008).

Ressalta-se, ainda, que a decisão de implementar a PML pode estar associada às características empreendedoras dos gestores que a consideram como geradora de novas oportunidades de negócios e inovações, visando a obter vantagens competitivas e sustentabilidade. Além disso, a implementação também pode estar relacionada às ligações entre os objetivos comerciais e as políticas referentes às questões ambientais e de responsabilidade social da empresa. Estas políticas impulsionam a adoção e implementação da PML, propiciando, por fim, a geração de inovação nas empresas participantes ao longo das cadeias produtivas (CHRISTIE eal, 1995).

No ano de 1999, o CNTL, o SEBRAE Nacional e o Conselho Empresarial Brasileiro para o D esenvolvimento Sustentável (CEBD S) iniciaram um trabalho em conjunto para promover o desenvolvimento sustentável nas micro e pequenas empresas, disseminando as práticas da PML e da ecoeficiência, com 0 acréscimo de mais duas questões no modelo de PML adotado: a gestão organizacional e 0 aspecto comportamental. Estas ações atuariam como ferramentas para aumentar a competitividade, a inovação e a responsabilidade socioambiental no setor produtivo brasileiro. D esta forma, as etapas da PML foram incrementadas, envolvendo: i) planejamento e organização; ii) diagnóstico; iii) medições e definições de indicadores; iv) estudo da viabilidade técnica, econômica e ambiental; e v) implementação e plano de continuidade (NASCIMENTO; LEMO S; MELLO, 2008).

\section{PROCEDIMENTOSMETODOLÓGICOS}

Esta pesquisa é do tipo exploratória - descritiva e se caracteriza pela natureza qualitativa. Utilizou-se da pesquisa bibliográfica e documental, visando a conhecer as fontes primárias e secundárias que abordam o tema e o problema explanados no referencial teórico (MARCO NI; LAKATO S, 1999).

A pesquisa de campo foi dividida em duas fases. Na primeira, utilizou-se a observação assistemática não participante, visitando a realidade da cadeia produtiva do agronegócio do caju cearense, com o intuito de colher informações sobre o setor estudado. Na segunda, utilizou-se um roteiro de entrevista semiestruturado para a coleta de informações (MARCO NI; LAKATOS, 1999). O roteiro de entrevistas foi segmentado em seis blocos temáticos, tendo por base os objetivos desta investigação. Ainda nesta etapa, foi constituído um painel de especialistas que atuam no setor do agronegócio do caju, selecionados após a fase de observação (LAVILLE; DIONNE, 1999). Os 20 especialistas que participaram desse painel foram escolhidos por se reunirem para debater sobre questões relacionadas ao setor em fóruns específicos, como, por exemplo: o Caju Nordeste e 0 AG RO PACTO (2008). Adotou-se o uso do critério de bola de neve (snouball) para a seleção dos especialistas a serem entrevistados, em que os participantes iniciais indicam os participantes seguintes. As entrevistas foram realizadas no período de abril e maio de 2009 e gravadas em vídeo, utilizando uma filmadora semiprofissional Sony HandycamHD R-FX 7, tendo produzido nove horas de entrevistas em gravação acumulada.

O Plano de Análise foi constituído visando à transcrição, organização e análise qualitativa dos dados e informações coletados por meio dos documentos compilados, das observações realizadas e da aplicação do roteiro de entrevista. Para isso foi utilizada a técnica da Análise Temática, que se insere no conjunto das técnicas da Análise de Conteúdo, cujo objetivo é evidenciar os itens de significação desde a descrição do corpus constituido, tendo por base as unidades de codificação ou categorias recortadas do conteúdo das entrevistas e dos documentos, sendo estas orientadas pelo problema e objetivos deste estudo (BARDIN, 1977).

Conforme explica Bardin (1977), esse diálogo entendido à luz de categonias e informações contextuais variadas faz emergira interpretação como elemento intrínseco ao processo de pesquisa. Com base nestes procedimentos, foram percorridas as diferentes fases de análise, entre estas: i) transcrição, constituição do copuse pré-análise; ii) leitura flutuante e a exploração do material com 0 estabelecimento de categorias e dositens de significação; iii) tratamento dos dados por inferência interpretação; e iv) confronto e discussão dos resultados obtidos com a teoria articulada.

Dessa forma, iniciando com as categorias teóricas, esse processo levou, no segundo momento, à redefinição das categorias empírico-analíticas em torno dos seguintes blocos temáticos: i) Gestão socioambiental na cadeia produtiva do caju

CONTEXTUS Revista Contemporânea de Economia e Gestão. Vol.7 - № 1 - jan/ jun/ 2009. (55-68). 
e a dinamização do sistema local; e ii) G estão da inovação sustentável e a dinamização do sistema local.

\section{Contextualização do agronegócio do caju no Ceará}

O Ceará representa $50 \%$ daárea cultivada de caju no País, estando esta subdividida em cinco polos: polo Pacajus, polo Aracati, polo Itapipoca, polo Camocim e polo Cariri, sendo ainda responsável pela geração de trinta mil empregos diretose cem mil empregos indiretos. Além disto, confere uma importância social em virtude da sua capacidade de geração de empregos na entressafra de outras atividades agropecuárias (FIEC, 2007; FRANÇA đal., 2008; FIG UEIRÊD O JÚNIOR, 2008).

A castanha de caju é o segundo produto na pauta de exportações cearense, gerando US\$140.515.788 em 2006, cerca de três quarto do volume total exportado, enquanto o mercado interno produz cerca de R\$ 72 milhões (FIEC, 2007).

0 mercado da amêndoa da castanha possui um destaque histórico que possibilitou a criação de um centro de pesquisa avançado voltado para o desenvolvimento tecnológico do caju. D esta forma, surgiu o atual Centro Nacional de Pesquisas da Agroindústria Tropical (CNPAT), ou mais comumente conhecida por E MBRAPA Agroindústria Tropical, que congrega um grande número de especialistas voltados para questões de melhoramento genético, manejo, pós-colheita e tecnologia de alimentos relacionados ao caju (ARAÚJO; PAULA PESSOA; LEITE, 1996).

\section{ANÁLISE E DISCUSSÃO DOSRESULTADOS}

Buscando ressonâncias na literatura articulada na primeira fase deste artigo, se expõe a seguir a análise final baseada nas categorias empírico-analíticas definidas durante o processo interpretativo do estudo.

$5.1 \mathrm{G}$ estão socioambiental na cadeia produtiva do caju ea dinamização do sistema local

Na análise documental das atas compiladas nas reuniões do Fórum do AGROPACTO (2007a; 2007b; 2007c; 2007d; 2007e; 2007f), evidenciou- se a existência de ampla rede de colaboração entre as diversas organizações e agentes envolvidos no agronegócio do caju cearense, pressupondo um contexto favorável para a criação, partilha e utilização do conhecimento, tendo em vista a sustentabilidade do setor (CASTELLS, 1999; BALESTRIN; VARGAS, 2004). Conforme o tema das entrevistas articulado, contudo, se faz necessário iniciar um trabalho de "mútuo apoio", visando a integrar mais estreitamente esta base de conhecimento, desenvolvida interativamente na rede, com os processos de aprendizagem e inovação no decorrer da cadeia produtiva do agronegócio do caju (LUNDVALL, 2001, 2002; CO RRÊA; CORREAA, 2004; LAMBERT, CO OPER; PAGH, 1998). D esta forma, as questões expressas pelos especialistas possibilitam inferências sobre a existência de um sistema local de inovação, envolvendo a cadeia produtiva do agronegócio do caju cearense, porém, desafios são apontados no sentido de se aprimorar a gestão dos relacionamentos e integração em rede dos diversos participantes e projetos:

Um sistema local de inovação tem algumas características importantes. Você precisar ter um centro de pesqui- sa. Você precisa ter um centro de formação de pessoas e aqui nós podemos falar das universidades, por exemplo. Você precisa ter instituições de fomento, Banco do Nordeste, SEBRAE, outros bancos. Você precisa também de organizações que dão suporte e que geram políticas, que favoreçam a inovação, aqui no caso do Ceará, nos temos a FUNCAP, a própria Secretaria de Ciência e Tecnologia (SECITECE). Na área de pesquisas, temos a EMBRAPA, o NUTEC, etc. Então se nós considerarmos o arcabouço institucional que caracteriza um sistema local de inovação, o Ceará tem todos os elementos para que o tema caju passe a ser objeto de preocupação de todos. Ele poderá estar inserido num sistema local de inovação, para o qual ele poderá se beneficiar se a cadeia produtiva do caju se articular corretamente com esses agentes. (Trecho da Entrevista 16).

Talvez ainda não se complete como um sistema. A pesquisa eu acho que está muito avançada. Do ponto de vista da integração entre essa pesquisa e a ponta e 0 produtor rural efetivamente existe uma desarticulação que precisa ser resolvida. (Trecho da Entrevista 1).

Nesse contexto, a consolidação dos temas analisados possibilitou a descrição da cadeia produtiva do agronegócio do caju, na tentativa de buscar melhor articulação entre os agentes e a gestão de seus gargalos, visando à dinamização do sistema local no qual esta está inserida, conforme um dos entrevistados:

A cadeia produtiva do agronegócio caju é constituída por fornecedores de insumos para a produção e para todo o espectro da cadeia como um todo: temos os produtores pequenos, médios, grandes, envolvendo até vinte mil, trinta mil hectares de produção de cajueiro. Temos as indústrias processadoras como o próximo elo. Tanto indústrias grandes, como médias, como as pequenas, quanto às mini-fábricas. As indústrias processadoras, o sistema de distribuição para o mercado interno quanto para o mercado externo (...) com um componente adicional a esse elo que são os brokess, aqueles que fazem a intermediação da venda da castanha de caju para o exterior. E temos, finalmente, os distribuidores, tanto aqui no Brasil como no exterior e os consumidores finais. Então esses seriam os elos principais da cadeia produtiva. (Trecho da Entrevista 16).

O s especialistas entrevistados ligados às organizações de classe e governamental participantes do sistema local nominaram a existência de um grupo de apoio - Núcleo de Monitoramento Ambiental - NUMA. Neste âmbito, sobressaem-se os temas expressos pelo coordenador de cadeias produtivas da Federação das Indústrias do Estado do Ceará (FIEC), focalizando o trabalho desse grupo especializado em gestão socioambiental, que fornece apoio a todas as indústrias que produzem impacto ambiental, inclusive as indústrias de beneficiamento da castanha de caju. Com base nessa constatação, foram extraídos temas do crpus analítico que revelam a ocorrência da gestão socioambiental com o aproveitamento dos resíduos, sobretudo, nas médias e grandes indústrias de beneficiamento da castanha do caju participantes da cadeia:

Nós trabalhamos com as três dimensões da gestão socioambiental: a gestão dos efluentes industriais, a dos gases e os resíduos sólidos também. D entro desse 
processo entra agora a coleta seletiva. 0 intuito é destinar cada um dos resíduos de forma correta, agredir ou não agredir, ou agredir ao mínimo 0 ambiente. E isso a gente tem de certa forma um retorno financeiro para a empresa. E a nossa preocupação é também verificar junto a comunidade, como a população, já que a fábrica está inserida num ambiente urbano, reage a poluição ambiental. A gente tem recebido bons resultados da comunidade. (Trecho da Entrevista 14).

Corroborando esta análise temática, e apesar de não se constatar a gestão preventiva de uma produção mais limpa, evidencia-se que a implementação de uma estratégia socioambiental, por intermédio da gestão dos resíduos gerados e aproveitados na própria cadeia ou em cadeias de outros produtos, está possibilitando o surgimento de inovações em processos e produtos em prol da sustentabilidade do setor (FERREIRA, 2006; NASCIMENTO, LEMOS E MELLO, 2008; BELL; PAVTT, 1993):

No processamento da castanha tem o resíduo da casca e o LCC que não é extraído. Isso era um problema para o setor porque não tinha onde colocar essa casca. Hoje a casca é toda vendida para queimar em caldeiras das grandes indústrias, em vez de se consumir produtos como madeira, se utiliza a casca. D esta forma algumas fábricas que utilizam a casca da castanha geram energia em benefício do seu próprio sistema energético. É também uma forma desse ciclo se completar dentro da cadeia. Como ele também se completa fora da cadeia, no momento em que você utiliza o LCC para a produção de diversos produtos mais nobres, como os aditivos e os pós de fricção. (Trechos das Entrevistas 1, 3, 5 e 8).

No momento que você faz a substituição de copas, esta gera resíduos que podem ser utilizados como composto orgânico, através de um processo de biodegração que posteriormente poderá ser aproveitado na própria cadeia como adubo orgânico nos próprios cajueirais. (Trecho da Entrevista 4).

A introdução da queima da casca e autilização de madeira proveniente da substituição de copas foram objetos de fiscalização e acompanhamento dos órgãos de proteção ambiental, como o Instituto Brasileiro de Recursos Naturais Renováveis e Meio Ambiente (IBAMA) e a Superintendência Estadual do Meio Ambiente (SE MACE). Nesses casos, foram regulamentados a utilização de filtros nas chaminés das fábricas de beneficiamento da castanha (LEITE, 1994) e a liberação do emprego da madeira da substituição de copas na queima por não considerá-la como desmatamento de floresta nativa. Alguns especialistas comentaram sobre 0 assunto: "Os processadores maiores devem utilizar filtros na emissão de fumaça quando da queima da casca da castanha, após extração do LCC" (Trecho da Entrevista 5).

Você tem, eu diria três órgãos que regulamentam, que tratam dessa parte ambiental no estado do Ceará. Uma é o IBAMA que é nacional. No caso específico, eu posso dar um exemplo, quando estavam utilizando a madeira do caju dos tratos culturais para a queima, houve uma interferência pesada do IBAMA, mas foi justificado oficialmente pela instituição de pesquisa que aquela madeira era resultado de uma atividade de manejo da cultura, portanto não trazia nenhum malefício ao meio ambiente. No caso estadual é a SEMACE que tem interferido, principalmente, no que diz respeito à emissão de resíduos, ou à vazão desses resíduos em fluxo d'água, etc. Tem feito algumas exigências, como também a parte do filtro, da filtragem das caldeiras que estão sendo utilizadas com essa matéria prima. [...]. (Trecho da Entrevista 3).

Considerando as evidências da existência de um sistema local de inovação, ressalta-se a necessidade para maior dinamização desse sistema, por via da eficiência das operações atuais, com melhorias contínuas nos sistemas de produção, da busca de opções para o futuro, que possibilitem a criação de valores, melhorando as posições competitivas das empresas e re-configurações da rede de relacionamentos entre os agentes econômicos envolvidos (VASCO NCELO S, 2001). Neste âmbito, a preocupação com a gestão socioambiental das empresas participantes ao longo da cadeia produtiva do agronegócio do caju é um fator que se realça, sobretudo, com a quantidade de pedúnculo desperdiçada.

Um dos grandes problemas da cajucultura é exatamente o não aproveitamento do pedúnculo do caju. Nós entendemos que há um campo muito amplo para se trabalhar com a questão relacionada com o aproveitamento do pedúnculo. Cerca de 80 a $85 \%$ do pedúnculo é desperdiçado. (Trecho da Entrevista 4 e 15).

A castanha do caju é um dos principais itens na pauta de exportação cearense, hoje se tem uma pressão muito grande dos países asiáticos que cultivam o caju. $\mathrm{Na}$ Africa também o cultivo do caju se alastra, neste sentido é uma necessidade estar sempre inovando e buscando alternativas. Aqui o diferencial brasileiro consiste na tentativa de buscar o aproveitamento do pedúnculo. (Trecho da Entrevista 15)

Diversos blocos temáticos ressaltaram a grande variedade de produtos e subprodutos que poderiam ser processados de forma inovadora, possibilitando novas oportunidades de mercado. Neste tema, os entrevistados diversificaram as possibilidades de inovações e mercados quanto aos novos processos e produtos que poderiam ser gerados à base do aproveitamento do pedúnculo (PAIVA, 1997; LIMA, 2004; G ALVÃO, 2006; BURLAMAQUI; PRO ENÇA, 2003):

Temos, também, a pasta do caju que se usa de forma semelhante à pasta de amendoim. São desenvolvimentos da pesquisa do NUTEC e que a EMBRAPA também participou. $O$ pó do caju que pode ser usado na fabricação de pães, na mistura com o trigo. Todas estas tecnologias foram desenvolvidas, testadas e estão aí na busca de empreendedores. Além desses produtos, nós destacamos a goma de caju que é retirado do caule, da sangria da casca do cajueiro que pode ser utilizada na fabricação de colas e ou cápsulas de medicamentos que são digeríveis, não são tóxicas. As colas que já vem com algum princípio ativo no combate a traças, insetos, etc. E recentemente temos casos de empreendedores que estão fabricando aguardente do caju, até perfumes do caju usando as essências importadas, com produtos inovadores utilizando o álcool produzido do caju para a 
composição desses perfumes. E falando em álcool é outro subproduto que poderemos estar desenvolvendo e testando a sua viabilidade econômica porque 0 pedúnculo do caju também produz álcool. (Trecho da Entrevista 16).

Além o suco de caju, a cajuína, fibras e doces cristalizados, o hambúrguer de caju, e ainda para ração animal, a principal oportunidade para aproveitamento do pedúnculo é a fabricação do suco clarificado e desodorizado de caju, espécie de filé de outros sucos, que poderá competir com o suco de maçã no mercado internacional. (Trecho da Entrevista 5).

É interessante que o pedúnculo tem muita utilização que ainda não estamos usando, como é o caso do pigmento. A Agência Nacional de Vigilância Sanitária (ANVISA) proibirá a partir de 2010 os corantes artificiais. E o caju tem uma fonte de corante amarelo, sendo outra possibilidade de agregação de valor para a cadeia produtiva. Abrindo possibilidades para 0 surgimento de elos com outras cadeias produtivas que trabalham, principalmente, com biotecnologia. (Trecho da Entrevista 9).

Temas extraídos das entrevistas com os especialistas identificaram os seguintes gargalos, elos fortes e fracos ao longo da cadeia produtiva do agronegócio do caju anteriormente descri- ta: i) elevada concorrência, depreciação da amêndoa da castanha do caju e problemas cambiais; ii) desperdício do pedúnculo, descobrir alternativas de uso para o caso da produção realizada a partir de cajueiro gigante; iii) preço elevado dos insumos básicos, por exemplo, as mudas enxertadas; iv) baixa produtividade do produtor e, consequentemente, uma baixa rentabilidade; $\mathrm{e}$ v) desarticulação da cadeia produtiva com a presença de vários atravessadores que comprometem os preços e a qualidade do produto que chega até o consumidor final (PAULA PESSOA; LEITE, 1998; AG RO PACTO, 2007a; FRANÇA đal., 2008).

O pções para um melhor gerenciamento dos resíduos, mediado pela possível implementação de uma metodologia preventiva do tipo produção mais limpa, foram confirmadas por diversos especialistas como ferramenta para aumentar a sustentabilidade com a geração e a difusão de inovações, como alternativa de geração de renda e trabalho e ampliação de novos espaços de negócios e no mercado, principalmente quando considerados os seguintes elos da cadeia produtiva: fornecedores de insumos; pequenos produtores agrícolas e processadores, tanto da amêndoa, como do pedúnculo (BURLAMAQUI; PROENÇA, 2003; NASCIMENTO; LEMO S; MELLO, 2008; CORREA A; CORREA A, 2004; LAMBERT; CO O PER; PAGH, 1998; BELL; PAVITT, 1993).

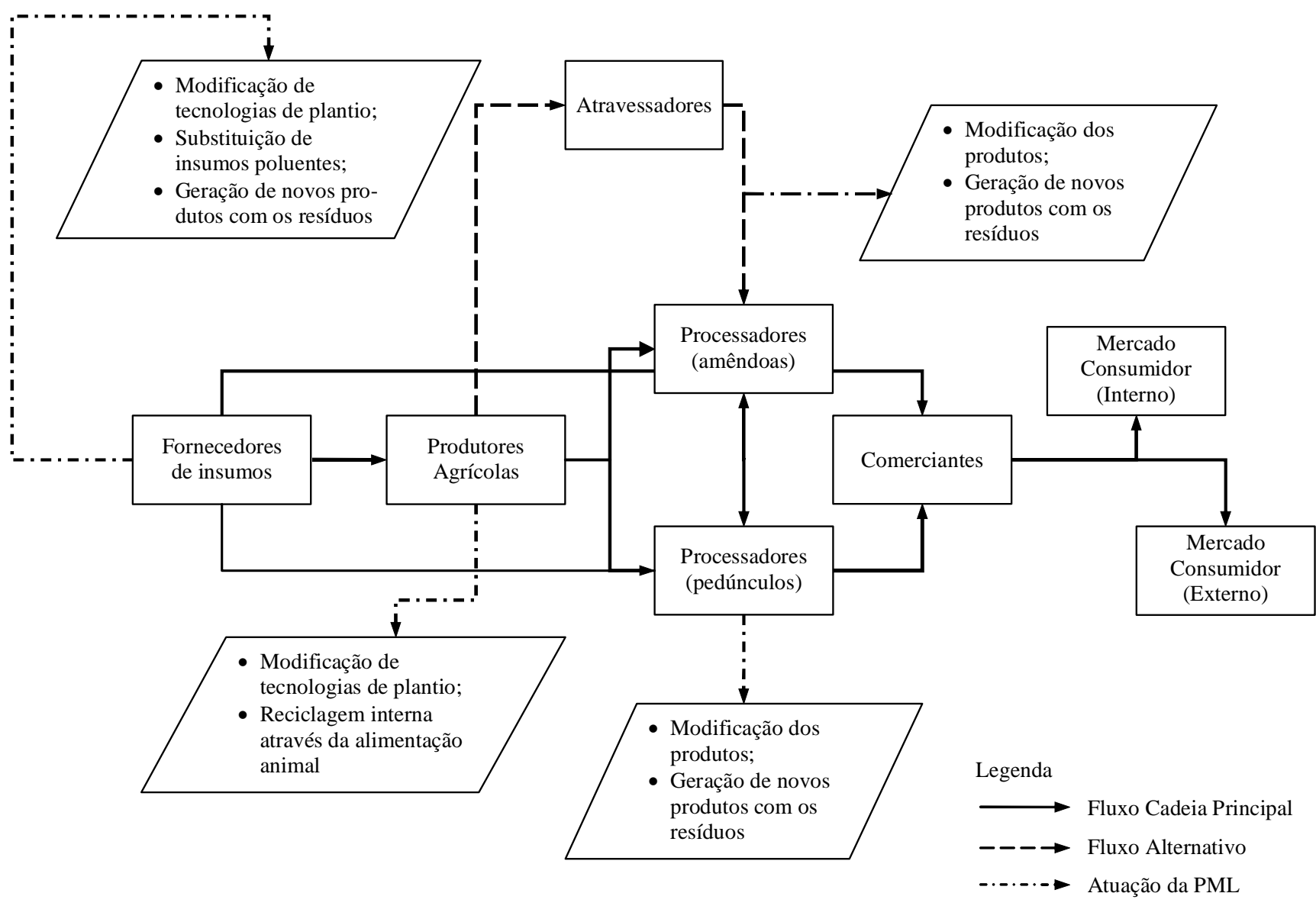

Figura 2: Sugestões para a adoção preventiva da PML na cadeia produtiva

Fonte: Elaborada pelos autores, com base nos dados da pesquisa. C CONTEXTUS Revista Contemporânea de Economia e Gestão. Vol.7 - № 1 - jan/ jun/ 2009. (55-68). 
Considerando os gargalos identificados pelos especialistas e com base na articulação desses temas de debate foi possivel analisar os efeitos da gestão socioambiental com a possível implementação preventiva da Produção Mais Limpa e suas implicações na sustentabilidade das empresas participantes da cadeia produtiva do caju. A Figura 2 permite a identificação de pontos a serem aperfeiçoados no âmbito da cadeia produtiva com aintrodução preventiva de ferramentas da Produção Mais Limpa, ocasionando e difundindo inovações, ao propiciar mudanças nos processos, produtos e formas da gestão das empresas (LEMOS, 1998; GASI; FERRE IRA, 2006; BERKHO UT; GREEN, 2002; BELL; PAVITT, 1993; CHRISTIE eal., 1995).

Vale ressaltar e conforme temas analíticos, algumas das alternativas de produtos e processos inovadores apresentados como decorrentes da gestão socioambiental ao longo da cadeia produtiva do caju estão em fase de finalização de pesquisas nos laboratórios de pesquisa e desenvolvimento $(P \& D)$ da E MBRAPA ou ainda são produzidos de forma artesanal, portanto, sem uma estrutura industrial devidamente formalizada. 0 caso do corante natural obtido de pigmentos do caju é um bom exemplo disto, pois o projeto concluído atenderá uma forte demanda que surgirá quando da regulamentação da ANVISA.

\subsection{G estão da inovação sustentável ea dinamização do sis- tema local}

O CNPAT da EMBRAPA Agroindústria Tropical destaca-se com o desenvolvimento de inovações sustentáveis para o setor. Algumas dessas já estão parcialmente difundidas e merecem destaque, como o clone de cajueiro anão precoce e a substituição de copas. O s clones de cajueiro anão precoce são desenvolvidos visando a atender às diversidades climáticas das áreas de cultivo e aos processamentos da castanha, do pedúnculo ou do caju de mesa (LEITE, 1994; PAULA PE SSOA; LEITE, 1998; FIGUEIRÊD O JÚNIOR, 2008; FRANÇA $\notin a$. ., 2008). O s trechos temáticos que se seguem ressaltam a asserção de Loiola e Ribeiro (2004), para quem inovar depende de saberes tácitos, localizados e cumulativos, estando as capacidades de inovação e aprendizagem fortemente enraizadas na estrutura social, institucional e produtiva de cada região, que podem ser encontrados, por exemplo, em aglomerações de pequenas e médias empresas interligadas ao longo de cadeias produtivas. Segundo a afirmação do consultor da Secretaria de Ciência e Tecnologia do Estado do Ceará- SECITECE, percebe-se a importância dessas inovações para a sustentabilidade da cadeia produtiva do caju:

\footnotetext{
0 advento do cajueiro anão precoce foi o grande passo que ocorreu do ponto de vista de tecnologia inovadora para o setor. Esse trabalho foi iniciado em 1965. Hoje nós temos vários clones, uns inicialmente lançados na década de 80 pela extinta Empresa Agropecuária do Estado - EPACE e posteriormente quando a EMBRAPA assumiu a estação experimental de Pacajus. Isso na verdade deu um novo alento na questão de inovação tecnológica, por uma série de razões: a questão da produtividade, a questão do porte da planta, a questão de período de safra mais longo tem uma série de vantagens. (Trecho da Entrevista 4).
}

Vários trechos selecionados das entrevistas e da análise documental ressaltaram a importância - das tecnologias dos clones, dos processos de substituição de copas, de armazenagem com a adoção de boas práticas de cultivo e um conjunto de tecnologias de pós-colheita e de transporte e ainda, da venda de castanha na bolsa de mercadorias, da entrada no mercado de créditos de carbono, da denominação geográfica de alguns produtos elaborados a partir do caju - que a iniciativa privada passou e poderá testar e desenvolver com o acompanhamento dos pesquisadores da EMBRAPA e das universidades; portanto, corroborando a noção de que as inovações como transformações de uma descoberta em uma nova prática podem ser vistas como reconfigurações de sistemas de atividade econômica, resultando na dilatação do espaço econômico, motivados pela percepção de oportunidades de mercado (VASCO NCELO S, 2001; BURLAMAQUI; PROENÇA, 2003):

\begin{abstract}
Nós acreditamos que aconteceram mudanças radicais e que de certo modo já começam a apresentar impactos positivos especialmente no que diz respeito à produtividade e sustentabilidade. Essas mudanças estão ligadas diretamente ao advento inovador dos clones de cajueiro anão precoce. Esta tecnologia e todo o seu processo produtivo, hoje muito avançado abriram mercados inclusive, para o pseudofruto do caju que hoje é comercializado no período da safra pelos turistas que visitam o estado do Ceará e já chega ao mercado nacional. (Trechos das Entrevistas 2 e 7).
\end{abstract}

Uma inovação muito importante que teve e ainda tem impacto é a substituição de copas de cajueiro improdutivo que a EMBRAPA desenvolveu e comprovou nas propriedades agrícolas através da parceria com a iniciativa privada, e ainda todas as tecnologias de irrigação, adubação, podas, manejo, etc. (Trechos das Entrevistas 5,10 e 16).

Paralelamente à geração da inovação dos clones, Foram também desenvolvidas tecnologias para armazenamento do pedúnculo fresco possibilitando a introdução no mercado do chamado caju de mesa ou in natura que dura em torno de 24 a 48 horas ou ainda até 3 semanas. Esta inovação viabilizou um mercado de caju de mesa para o Sul e Sudeste do país, para distancia de até $4.200 \mathrm{~km}$ por transporte refrigerado. (Trechos das Entrevistas 10 e 16).

Um nicho de mercado é a questão do caju de mesa
livre de produtos químicos projeto em desenvolvimento
pela EMBRAPA. Em algumas comunidades as ONG
vêm incentivando as pessoas a terem esse cuidado e
despertando para esses nichos importantes, principal-
mente, para o pequeno produtor das mini fábricas que
poderia controlar isso com mais facilidade. (Trecho da
Entrevista 4).

Esses blocos temáticos ressaltam a possibilidade de ampliação dos espaços econômicos definidos por Schumpeter(1997), ao envolver aintrodução de um novo método de produção, com a conquista de aproveitamentos alternativos da fonte de matérias-primas e insumos, 0 estabelecimento de uma nova organização industrial e a consequente abertura de um novo mercado. 
A atuação do centro de pesquisa da EMBRAPA Agroindústria Tropical situa o Estado do Ceará como o centro da inovação do agronegócio do caju; contudo e apesar das unânimes opiniões sobre a importância da geração dessas inovações para a sustentabilidade do setor, se releva que a adoção e difusão dessas tecnologias não alcançaram boa parte dos pequenos produtores rurais (BELL; PAVITT, 1993):

O Brasil é o mais avançado país na pesquisa relacionado à cajucultura. 0 que está precisando é que esta pesquisa efetivamente chegue de uma forma ampla e oportuna no campo, com equipamentos e inovações efetivamente disseminados. Então do ponto de vista da pesquisa, nós podemos dizer que o país está bastante avançado. D o ponto de vista da integração entre essa pesquisa e a ponta e o produtor rural, as mini fábricas efetivamente existe uma desarticulação que precisa ser resolvida. (Trecho da Entrevista 1).

0 ambiente existente não é favorável à disseminação da inovação, apesar dos esforços da EMBRAPA, as novas tecnologias desenvolvidas não são adotadas pelos produtores porque estes não têm capital, nem conhecimento para tal. Aí eles entravam o processo por conta das técnicas que eles não têm por falta de acesso a informação, ao conhecimento básico e ao crédito. (Trecho da Entrevista 5 e 17).

O Ceará hoje é onde se localiza o maior centro de referencia de desenvolvimento tecnológico para o caju, referencia mundial. A transformação disso tudo num sistema local de inovação, atuante, produtivo e sustentável, que tenha resultado de impacto na cadeia produtiva, só depende de um processo de coordenação em rede. (Trecho da Entrevista 16).

Destacou-se da análise, contudo, aatuação das minifábricas de processamento da castanha de caju como importante tecnologia social, com o objetivo de aumentar a agregação de valor para os pequenos produtores. Neste sentido, o programa das minifábricas é um bom exemplo de introdução de conhecimentos tecnológicos diretamente aos pequenos produtores, gerando inovações sustentáveis ao conectar as dimensões ambientais com aquelas econômicas e sociais (BERKHOUT; GREEN, 2002). As minifábricas receberam apoio de órgãos financiadores e prêmios na categoria "Tecnologia Social":

Cerca de 10 anos a EMBRAPA vem trabalhando na tecnologia das mini-fábricas. Trata-se da organização dos pequenos produtores, baseado no núcleo familiar, moradores de uma mesma localidade, para que eles produzam e, eles mesmos, processem os produtos em micro fábricas. A EMBRAPA desenvolve os equipamentos e processos para isso. A 5 ou 6 anos atrás ganhamos 0 prêmio nacional da Fundação Banco do Brasil na categoria de Tecnologia Social, e isso tem sido bastante interessante porque essas pessoas tem tido oportunidades de eles mesmos participarem de exportações, etc. Talvez o Ceará seja o estado que tenha mais mini-fábricas e o objetivo foi justamente inserir essas pessoas no mercado a partir de um treinamento voltado para que eles mesmos manipularem os processos eprodutos. Não só catarem a castanha que está ali no chão e venderem para outras pessoas, mas deles mesmos selecionarem a castanha, quebrarem, retirarem a amêndoa e fazerem a exportação. [...] Talvez esse seja um dos melhores exemplos da associação da tecnologia com inserção e inclusão social dos mais carentes que simplesmente tinham 0 caju nas suas terras e que colhiam e entregavam para um atravessador. (Trecho da Entrevista 10).

O programa de criação de minifábricas foi amplamente difundido no Nordeste, mas hoje apresenta alguns problemas estruturais, principalmente quanto às questões relacionadas ao seu gerenciamento. 0 comentário a seguir demonstra a importância dessas na integração de novos elos da cadeia produtiva do caju, apresentando tanto problemas como soluções, sobretudo ao salientar que a possível implementação preventiva de ferramentas da Produção Mais Limpa poderá propiciar mudanças nos processos, produtos e formas da gestão das empresas (LEMOS, 1998; GASI; FERREIRA, 2006; CHRISTIE eal, 1995).

A ideia da minifabrica é uma ideia consagrada. Precisamos fazer uma série de ajustes nas questões das minifábricas, mas de qualquer maneira é uma questão consagrada. [...] 0 grande passo que poderia ser dado seria a questão do entrelaçamento: setor industrial e o setor de produção. Seria o papel das minifábricas nesse meio campo. As mini-fabricas podem exercer um papel fundamental na questão da reorganização desses elos e por razões óbvias. Você teria minifábricas não só na parte do pedúnculo do caju, como na parte da castanha de caju. 0 grande problema que se tem das mini-fábricas é a questão relacionada com a gestão. E também uma visão paternalista, assistencialista que tem que ser quebrada. E aí vem o papel de profissionalizar a gestão das mini-fábricas. (Trecho da Entrevista 4)

Estas constatações evidenciam a necessidade da dinamização do sistema local mediante a iniciativa das organizações de apoio e da implementação de novas práticas da gestão e de políticas públicas ao longo da cadeia produtiva do agronegócio do caju, visando ao adensamento das interações e coordenação do intercâmbio, propiciando, por fim, a geração e difusão de inovações sustentáveis (LUNDVALL, 2002; LOIOLA; RIBEIRO, 2004; BERKHOUT; GREEN, 2002; BELL; PAVITT, 1993; CHRISTIE \&al, 1995).

\section{CONSIDERAÇÕESFINAIS}

A criação de sistemas agroindustriais sustentáveis é uma busca constante junto às cadeias produtivas agropecuárias do Ceará. As evidências articuladas na análise de vários blocos temáticos revelam a existência de um conjunto de organizações de apoio e de micro, pequenas e médias empresas, caracterizando um sistema local de inovação que interagem em prol da sustentabilidade da cadeia produtiva do agronegócio do caju.

Vários trechos selecionados das entrevistas e da análise documental ressaltaram a importância - das tecnologias dos clones, dos produtos advindos com a substituição de copas, dos processos de armazenagem com a adoção de boas práticas de cultivo e um conjunto de tecnologias de pós-colheita, de transporte e, ainda, das possibilidades da venda de castanha na bolsa de mercadorias, da entrada no mercado de créditos de carbono, da denominação geográfica dos produtos, da questão 
do caju de mesa produzido de forma orgânica, enfim, o Centro Nacional de Pesquisas da Agroindústria Tropical (CNPAT) da EMBRAPA Agroindústria Tropical, participante do sistema local - se destaca com o desenvolvimento de inovações visando 0 desenvolvimento ao agronegócio do caju do Nordeste.

Revelou-se da análise, porém, a necessidade da coordenação em rede no sentido de um maior adensamento dos relacionamentos entre os diversos agentes, visando a uma dinamização maior do sistema local, sobretudo, no sentido da adoção e difusão das práticas da gestão, manejo e produtos inovadores gerados pelos centros de pesquisa e desenvolvimento $(\mathrm{P} \& \mathrm{D})$ participantes.

Neste âmbito, destaca-se a preocupação com a gestão socioambiental com a criação de um grupo de apoio - Núcleo de Monitoramento Ambiental - NUMA, visando ao desenvolvimento de tecnologias e práticas que possibilitem 0 aproveitamento integral do caju. Particularmente, sobressaem-se as ações voltadas para o desenvolvimento, no decorrer da cadeia produtiva do caju, de produtos diferenciados com boa agregação de valor, tornando, por exemplo, o processamento do pedúnculo do caju em uma nova oportunidade de negócios e mercados.

Ressalta-se ainda da análise o fato de que muitos dos gargalos identificados ao longo da cadeia produtiva do caju poderão ser aperfeiçoados após a possível implementação preventiva de uma abordagem do tipo Produção Mais Limpa, ensejando e difundindo inovações ao propiciar mudanças nos processos, produtos e formas da gestão das empresas.

Nesse sentido, o programa das minifábricas, como importante tecnologia social participante do sistema local, demonstra a importância destas na integração de novos elos da cadeia produtiva do caju, apresentando-se como um bom exemplo da difusão de conhecimentos tecnológicos diretamente aos pequenos produtores, dando azo a inovações sustentáveis ao conectar as dimensões ambientais com aquelas econômicas e sociais.

Com base nessa discussão, considera-se que o pressuposto elaborado para esta pesquisa foi em parte confirmado ao se perceber que a "inovação sustentável" surge da gestão socioambiental, conectando as dimensões ambientais com aquelas econômicas e sociais e dinamizando, em consequência, o sistema local.

Por outro lado e apesar da grande variedade de produtos e subprodutos desenvolvidos, com boa possibilidade de agregação de valor para a cadeia produtiva e em associação com outras cadeias e que poderiam ser processados de forma inovadora, a partir, por exemplo, do aproveitamento do pedúnculo como a fabricação do suco clarificado e desodorizado e a utilização como corante do pigmento amarelo do caju - esses, encontram entraves na difusão e uso por grande parte dos pequenos produtores rurais.

Esses blocos temáticos ressaltam a necessidade da gestão da inovação sustentável de forma ampla, que poderá ser obtida com a implementação preventiva de uma abordagem do tipo PML ao longo das empresas participantes da cadeia produtiva, no sentido de que os resultados obtidos nos centros de pesquisa e desenvolvimento $(\mathrm{P} \& \mathrm{D})$ sejam efetivamente difundidos, dilatando, assim, os espaços econômicos definidos por
Schumpeter (1997), ao envolver a introdução de novos métodos de produção, com a conquista de aproveitamentos alternativos da fonte de matérias-primas e insumos, o estabelecimento de uma nova organização industrial e a consequente percepção das oportunidades de novos negócios.

Sugere-se, por fim, que a recém-formada Câmara Setorial do Caju desenvolva trabalhos iniciais para melhor articulação da cadeia produtiva e em seguida atue junto aos Governos Estadual e Federal na formulação de políticas públicas que incentivem a adequação dos produtores e processadores em prol da dinamização do sistema local e do desenvolvimento sustentável da região.

\section{REFERÊNCIAS}

AG RO PACTO - PACTO DE CO OPERAÇÃO DA AG RO PECUÁRIA CEARENSE. Situacão e pespeetiva da cadka produtiva do caju, mo mmon no Brasil enoCerá Fortaleza, 2007a. D isponível em: <http:/ / www.agropacto-ce.org.br/ palestras/ 31\%2007\%2007.pdf>. Acesso em: 17 de janeiro de 2008.

. Potenaialidades elimitaçós do segnento agíada da cadia do caju Fortaleza, 2007b. Disponível em: <http:/ / www.agropactoce.org.br/ palestras/ 24\%2007\%2007.pdf>. Acesso em: 17 de janeiro de 2008.

Opatumidades elimitaçes da cadkia produtiva do caju - segmento industrial da castanha. Fortaleza, 2007c. D isponível em: <http:/ / www.agropacto-ce.org.br/ palestras/ 31\%2007\%2007.pdf>. Acesso em: 17 de janeiro de 2008.

. Ananjo institurional para a compeitividade da cajualtura no Ceará Fortaleza, 2007d. Disponível em: <http:/ / www.agropactoce.org.br/ palestras/ 08\%2008\%2007.pdf>. Acesso em: 17 de janeiro de 2008.

I - Opatumidades e limitaçaes da cadkia produtiva do caju segmento industrial e comercial; II - Uso do pedúnculo na ração animal. Fortaleza, 2007e. D isponível em: <http:/ / www.agropactoce.org.br/ palestras/ 20\%2008\%2007.pdf>. Acesso em: 17 de janeiro de 2008.

Outros produtos da castanha e amêndoa do caju. Fortaleza, 2007f. D isponível em: <http:/ / www.agropacto-ce.org.br/ palestras/ 27\%2008\%2007.pdf>. Acesso em: 17 de janeiro de 2008.

Históica Disponível em: <http:/ / www.agropactoce.org.br/ Agropacto.htm>. Acesso em: 06 de junho de 2008.

ALMEIDA, F. Os desafios da sustentabilidade Rio de Janeiro: Elsevier, 2007.

ARAÚJO, J. P. P; PAULA PESSOA; P. F. A.; LEITE, L. A. S. Gestão estratégica de pesquisa e desenvolvimento em uma abordagem de agribusiness: o caso do Centro Nacional de Pesquisa de Caju da Embrapa. Rerista de Administraçãa São Paulo v. 31, n.4 p. 97101, out/ dez. 1996.

BALESTRIN, A.; VARG AS, L. M. A dimensão estratégica das redes horizontais de PMEs: teorizações e evidências. Reista deAdministração Contemparânea RAC, Rio de Janeiro: ANPAD, Edição Especial, v. 8, n.1, Jan./ Abr. 2004.

BARBIERI, J. C. Gestão ambiental empresarial: conceitos, modelos e instrumentos. 2. ed. São Paulo: Saraiva, 2007.

BARD IN, L. Análisedo conteúda Lisboa: Edições 70, 1977.

BATALHA, M. O. As cadeias de produção agro-industriais: uma perspectiva para 0 estudo das inovações tecnológicas. Revista de Administraçãa São Paulo, USP, v. 30, n. 42, p. 43-50, outubro/ novembro, 1995. 
Atlas, $200 \overline{8}$.

(coord.). Gestão Againdustrial. vol. 1. 3. ed. São Paulo:

BELL, M.; PAVITT, K. Technological accumulation and industrial growth: contrasts between developed and developing countries. Industrial and Corparate Change, v. 2, n.2, p. 157-211, 1993.

BERKHOUT, F.; GREEN, K. Managing innovation for sustainability: the challenge of integration and scale. Intemational Joumal of Immovation Management. v. 6. n. 3, p. 227-232, sep. 2002.

BURLAMAQUI, L.; PROENÇA A. Inovação, recursos e comprometimento: em direção a uma Teoria Estratégica da Firma. Reiista Brasileira de Inovaçãa v. 2, n. 1, p. 79-110, jun. 2003.

CASTELLS, M. A Sociedade em Rede A era da informação, economia, sociedade e cultura. Vol I; São Paulo: Paz e Terra, 1999.

CASTRO, A. M. G., COBBE, R. V., GOED ERT, W. J. Prospecção de demandas teendógicas: Manual Metodológico para o SNPA. Empresa Brasileira de Pesquisa Agropecuária. D epartamento de Pesquisa e Difusão de Tecnologia. Brasília: Embrapa-D PD, 1995.

; PAEZ, M. L. A.; GOMES, G. C.; CABRAL, J. R. Priorização de demandas da clientela de $\mathrm{P} \& \mathrm{D}$ em agropecuária. Revista de Administraçãa São Paulo, v. 31, n. 2, abril/ junho,1996.

; CRISTO, C. M. P. N. Cadeia produtiva: marco conceitual para apoiar a prospecção tecnológica. In: SIMPÓSIO DE GESTÃO DA INOVAÇÃO TECNOLÓG ICA, 22, 2002, Salvador. Anais.. Salvador: ANPAD, 2002.

;LIMA, S. M. V.; G OEDERT, W.J.; FREITAS FILHO, A. DE; CAMPOS, F. A. DE A ; VASCO NCELOS, J. R. P. Prospecção de D emandas Tecnológicas no Sistema Nacional de Pesquisa Agropecuária (SNPA). In.: CASTRO, A. M. G.; LIMA, S. M. V.; GOEDERT, W. J.; FREITAS FILHO, A; CAMPO S, F. A. DE A ; VASCO NCELOS, J. R. P. Cadkias produtivas e sistemas naturais: prospecção tecnológica. Brasília: Embrapa/ D PD, 1998.

CHRISTIE, I.; ROLFE, H.; LEG ARD, R. Cleaner production in industry: integration business goals and environmental management. Policy Studies Institute, London, 1995.

CORREAA, H. L.; CORREAA, C. A. Administracão deproducões eqpera coes manufatura e serviços: uma abordagem estratégica. São Paulo: Atlas, 2004.

DAROIT, D.; NASCIMENT, L. F. Dimensões da inovação sob o paradigma do desenvolvimento sustentável. In: ENCONTRO DA ASSO CIAÇÃO NACIO NAL D O S PRO GRAMAS DE PÓ S-GRADUAÇÃO EM AD MINISTRAÇÃO , 28, 2004, Curitiba. Anais.. Curitiba: ANPAD, 2004.

FIEC - FEDERAÇÃO DAS INDÚSTRIAS DO ESTADO DO CEARÁ. O desafio da cajucultura. Revista da FIEC. Fortaleza, v. 1, n. 6, novembro, 2007.

FIG UEIRÊD O JÚNIOR, H. S. D esafios para a cajucultura no Brasil: análise de competitividade e recomendações para 0 setor. Revista Econômica do Nardeste, Fortaleza, v. 39, n. 3, p. 371-394, jul./ set., 2008

FRANÇA, F. M. C.; BEZERRA, F. F.; MIRANDA, E. Q.; SOUSA NETO, J. M. Agronegóaio do caju no Ceará: cenário atual e propostas inovadoras. Fortaleza: Federação das Indústrias do Estado do Ceará, Instituto de D esenvolvimento Industrial do Ceará, 2008.

GALVÃ O, A. M. P. Aprovitamento da fibra do caju (Anacardium occidentale L.) na formilação de umproduto tipo hambúrguer. 2006. 64 p. Dissertação (Mestrado em Tecnologia de Alimentos). Universidade Federal do Ceará.

GASI, T. M. T.; FERREIRA, E. Produção mais limpa. In: VILELA JÚNIOR, A.; DEMAJOROVIC, J (O rgs.). Modkos e ferramentas de gestão ambiental: desafios e perspectivas para as organizações. São Paulo: Senac São Paulo, 2006. cap. 2. p. 41-84.

JABBO UR, C. J. C. Resgatando o conceito de tecnologia ambiental. In: ENCONTRO DA ASSO CIAÇÃO NACIONAL DOSPROG RAMASDE PÓ S-G RAD UAÇÃO EM AD MINISTRAÇÃ O , 31, 2007, Rio de Janeiro. Anais.. Rio de Janeiro: ANPAD, 2007.

LAMBERT, R.; COOPER, M.; PAG H. C. Supply Chain Management: implementation issues and research opportunities. The Intemational Jourmal of Logistics Management, v. 9, n. 2, 1998.

LAVILLE, C.; D IO NNE, J. A construção do saber: manual de metodologia da pesquisa em ciências humanas. Porto Alegre: Artmed; Belo Horizonte: Editora UFMG, 1999.

LEITE, L. A. S. A againdústria do caju no Brasil: políticas públicas e transformações econômicas. Fortaleza: EMBRAPA-CNPAT, 1994.

LEMOS, A. D. C. A produção mais limpa como gradara de inovação e competitividade o caso da fazenda Cerro do tigre. 1998. 182 p. Dissertação (Mestrado em Administração). Universidade Federal do Rio Grande do Sul.

LIMA, A. C. Estudb para agecação devalor aos produtos do caju: elaboração de formulações de fruta e castanha em barras. 2004.173 p. Tese (D outorado em Tecnologia de Alimentos). Universidade Estadual de Campinas.

LOIOLA, E.; RIBEIRO, M. T. F. Política de ciência, tecnologia e inovação como instrumento de governança para o desenvolvimento: uma proposta para o estado da Bahia. In: ENCONTRO DA ASSO CIAÇÃO NACIONAL D OSPROGRAMASDE PÓ S-GRADUAÇÃO EM AD MINISTRAÇÃO, 28, 2004, Curitiba. Anais... Curitiba: ANPAD, 2004.

LUNDVALL, B.A. National Systems of Innovation: towards a theory of innovation and interactive learning. London: Pinter Publishers, 1992. . Políticas de Inovação na Economia do Aprendizado. In: Parcerias Estratégicas, n. 10, p. 200-218, 2001.

. Imnovation gouth and social cohesion: the danish model. Chetenham, UK: Edward Elgar, 2002.

MARCO NI, M. A.; LAKATOS, E. M. Témicas de pesquisa. 4. ed. São Paulo: Atlas, 1999.

NONAKA, D.; TAKEUCHI, H. The Knowkedge Creating Company: how japanese companies create the dynamics of innovation. New York: Oxford University Press, 1995.

NASCIMENTO, L. F.; LEMO S, A. D. C.; MELLO, M. C. A. Gestão sociombiental estratégica. Porto Alegre: Bookman, 2008.

OLIVEIRA, L. G. L.; IPIRANGA, A. S. R. Sustentabilidade e inovação na cadeia produtiva da cajucultura cearense. In: SIMPÓ SIO DE GESTÃO DA INOVAÇÃO TECNOLÓGICA, 25, 2008, Brasília. Anais.. Brasília: ANPAD, 2008.

PAIVA, Francisco Fábio de Assis. Aproveitamento Industrial do Caju. In: CARVALHO, A. R.; TELES, J. A. (orgs.). Caju: negócio e prazer. Fortaleza: SETUR. G overno do Estado do Ceará, 1997. pp. 47-68. Capítulo 3.

PAULA PESSOA, P. F. A.; LEITE, L. A. S. Cadeia produtiva do caju: subsídios para a pesquisa e desenvolvimento. In: CASTRO, A. M. G.; LIMAS, S. M. V.; GOEDWERT, W. J.; FREITAS FILHO, A.; VASCONCELOS, J. R. P. (O rgs). Cadkias produtivas e sistemas naturais: prospecção tecnológica. São Paulo: Embrapa, 1998.

SCHUMPETER, J. A. Teria do Desenvduinento Econônica São Paulo: Nova Cultural, 1997.

SOUZA, S. O.; KLIEMANN NETO, F. J. D esenho e análise da cadeia produtiva de vinhos finos gaúchos. In: ENCONTRO DA 
ASSO CIAÇÃO NACIO NAL D O S PROG RAMAS D E PÓ S-GRADUAÇÃO EM AD MINISTRAÇÃO, 26, 2002, Salvador. Anais.. Salvador: ANPAD, 2002.

TID D, J.; BESSANT, J,; PAVITT, K. Gestão da inovaçãa 3 ed. Porto Alegre: Bookman, 2008.

UNEP - UNITED NATIONSENVIRONMENT PROGRAMME. Applying deaner production to MEAs global status report. Paris: Unep publication, 2006.

VARG AS, M. A. Proximidade teritaial, aprendizado e inovacãa um estudo sobre a dimensão local dos processos de capacitação inovativa em arranjos e sistemas produtivos no Brasil. 2002. 255 f. Tese de D outorado em Economia do Instituto de Economia da Universidade Federal do Rio de Janeiro, 2002.

VASCONCELOS, F. C. D a gestão do conhecimento à gestão da ignorância: uma visão co-evolucionária. Revista deAdministração de Empresas - RAE, v.1, n.4, São Paulo, out./ dez. 2001.

ZYLBE RSZTAJN. D. Políticas agnícolas e comério mundial "Agibusiness": conceito, dimensões e tendências. In: Fagundes. H. H. (O rg). Instituto de Pesquisas Econômicas Aplicadas. Brasília: IPEA, 1994 (Estudos de Política Agrícola, n. 28). 
